\title{
ESTUDO DO INPUT DE VALOR NO MEIO RURAL COM A CRIAÇÃO DE CIRCUITOS DE PROXIMIDADE, NO CONCELHO DE VISEU*
}

\author{
Rosa Maria Albuquerque Rodrigues ${ }^{\dagger}$ \\ Paulo Almeida Pereira
}

\begin{abstract}
Resumo: Este trabalho teve como objetivo estudar os circuitos de proximidade, que podem ser estabelecidos entre consumidores urbanos da cidade de Viseu, e produtores de produtos de origem animal e vegetal, que habitam as zonas rurais da cidade.

Este estudo pretende também contribuir para a abertura de um espaço de debate, onde venham a ser lançadas e discutidas ideias $e$ projetos que tenham como objetivo promover a dinamização destes circuitos de proximidade, no contexto da criação de riqueza e da sua distribuição mais igualitária, no contexto da preservação do mundo rural e da ruralidade do nosso concelho.

Para tal, foi eleito o método qualitativo de análise da informação recolhida através de entrevistas a clientes urbanos e a produtores rurais. Estes intervenientes foram escolhidos de uma forma aleatória, apenas respeitando alguns parâmetros para a sua seleção.

Demonstrou-se com este estudo que é possível estreitar relações entre o meio urbano e o meio rural do concelho de Viseu, identificando mais-valias que este relacionamento pode trazer a ambas as partes. Esta criação de valor vai para além da vertente meramente económica, que nem por isso deixa de ser determinante, promovendo também a criação e o estreitamento de laços sociais entre as duas comunidades.
\end{abstract}

\footnotetext{
* Este artigo foi elaborado a partir da dissertação de Mestrado em Gestão, especialização em Gestão de Recursos Humanos, defendida no Departamento de Economia, Gestão e Ciências Sociais, da Universidade Católica Portuguesa, em 2014 ${ }^{\dagger}$ Mestre em Gestão, especialização em Gestão de Recursos Humanos, Departamento de Economia, Gestão e Ciências Sociais, da Universidade Católica Portuguesa. Email: rodrigues.rosa@gmail.com

* Prof. Auxiliar - Departamento de Economia, Gestão e Ciências Sociais da Universidade Católica Portuguesa. E-mail: ppereira@crb.ucp.pt
} 
Palavras-chave: circuitos de proximidade, concelho de Viseu, consumidores urbanos, produtores rurais, produtos de origem animal e vegetal.

\title{
STUDY OF INPUT VALUE IN RURAL AREAS WITH THE CREATION OF PROXIMITY CIRCUITS, IN THE MUNICIPALITY OF VISEU
}

\begin{abstract}
This work aimed to study the circuits of proximity, that can be established between urban consumers in the municipality of Viseu, and producers of animal and vegetable origin, inhabiting the rural areas of the city.

This study also aims to contribute to the opening of a space for debate, where ideas and projects that aim to promote the revitalization of these circuits of proximity can be released and discussed, in the context of wealth creation and its more equal distribution, and in the context of preserving the countryside and the rural life of our county.

For this, it was elected a qualitative method of analysis of the information gathered through different interviews with farmers and urban customers. These players were chosen in a random manner, respecting only some parameters for its selection.

It was demonstrated with this study that it is possible to strengthen relations between urban and rural areas of the municipality of Viseu, identifying gains that this relationship can bring to both parties. This value creation goes beyond the purely economic aspect, which by no means ceases to be decisive, promoting also the creation and strengthening of social ties between the two communities.
\end{abstract}

Keywords: proximity circuits, municipality of Viseu, urban consumers, rural producers, animal and vegetable products

\section{INTRODUÇÃO}

Após muitos anos de indiferença, os produtos agrícolas e agroalimentares tradicionais são presentemente considerados como uma das bases fundamentais para a resolução dos problemas que apresenta o mundo rural.

A nível Europeu, a PAC - Política Agrícola Comum, foi concebida para dar resposta a uma situação de vincado défice alimentar na Comunidade e para ser aplicada a estruturas de agricultura características dos seis Estados Membros que à data a constituíam. 
"O discurso técnico incidiu em diretrizes que implicaram o aumento da produção e produtividade, bem como a intensificação e a especialização dos sistemas de produção. Hoje esta realidade está totalmente ultrapassada", (Tibério \& Cristóvão, 2005 p. 16).

As políticas europeias de desenvolvimento agrícola, trilham hoje não somente os caminhos da qualidade e da especificidade dos produtos agrícolas, como também os caminhos da diversificação de produção e da vantagem competitiva dos produtos locais e tradicionais.

Atualmente, é possível constatar que os agricultores investem essencialmente para colmatar as suas próprias necessidades alimentares, para fazerem crescer os seus rendimentos e para aumentarem o seu património. Porém, não é menos evidente, que o crescimento de produtividade no sector agrícola gera um aumento de outros bens e serviços rurais, criando simultaneamente empregos e aumento de rendimentos, que por seu turno estimulam a fixação de população em meio rural.

Segundo Cristas (2013, pp. 2-3):

Em Portugal existe uma grande diversidade/variedade de produtos agrícolas e agroalimentares locais, muitos deles reconhecidos como produtos de qualidade. Se durante alguns anos estes produtos locais não foram valorizados, verifica-se ultimamente o ressurgimento de uma cultura ligada ao regresso à terra e aos valores da ruralidade. Hoje em dia, os consumidores procuram consumir os produtos nacionais porque há um sentimento de contribuir para o incremento da economia nacional e para a defesa dos produtores e produtos nacionais. Para o fortalecimento deste sentimento têm contribuído diversas iniciativas que promovem o consumo de produtos nacionais e locais. Estas novas tendências do consumo criam novas oportunidades de mercado para as produções agrícolas e agroalimentares locais, riqueza que é necessário preservar e constitui um potencial que pode ser utilizado criando benefícios para os agricultores, os consumidores, os territórios e para a preservação do ambiente. Com a venda direta cria-se a possibilidade do preço reverter maioritariamente para os agricultores.

"Os produtos agrícolas e agroalimentares tradicionais, outrora esquecidos por investigadores, técnicos e decisores políticos estão hoje no centro das atenções, enquanto instrumento de desenvolvimento agrícola e rural de territórios particularmente desfavorecidos" (Tibério \& Cristóvão, 2005, pág. 15).

Este estudo visa refletir sobre os caminhos passíveis de serem trilhados para promover o desenvolvimento rural do concelho de Viseu, especialmente sobre os associados à produção e venda de produtos de 
produção rural de origem animal e vegetal, os seus circuitos de comercialização, e a importância dos circuitos de proximidade que se podem estabelecer entre a população rural e a população urbana.

\section{OBJECTIVOS DO ESTUDO E METODOLOGIA UTILIZADA}

A agricultura, tal como é encarada no conceito atual, gera dois tipos de ameaças à sua própria sustentabilidade. A primeira decorre da intensificação da atividade agrícola, consubstanciada na dominância das monoculturas e no uso excessivo de fertilizantes e outros químicos, assim como na utilização massiva de máquinas agrícolas. A segunda deriva da sobre utilização dos solos, que altera os recursos naturais e fragiliza os ecossistemas. Neste contexto, o melhor caminho para atingir um sistema alimentar sustentável parece ser o do estímulo da agricultura familiar.

Vários estudos a nível mundial, demonstram que o investimento na agricultura contribui para o crescimento económico e para a redução da pobreza em meio rural, onde vive, a nível mundial, a maior parte da população em situação de pobreza.

Atualmente, a conjuntura económica, e com ela o aspeto financeiro, têm dominado a atenção de grande parte dos cidadãos, dos média e da classe política.

Os autores Cipriano Pinheiro \& Pimentel de Castro Coelho (2011), sustentam que:

as despesas com a alimentação constituem um dos nossos grandes e graves problemas. Para podermos comprar o alimento que necessitamos temos de pedir emprestados 3,6 mil milhões de Euros por ano, ou seja, cerca de dez milhões por dia, ou, mais simplesmente, um euro por dia e por português! Acrescente-se que, nalguns casos, os países que nos emprestam o dinheiro são os mesmos que, depois, nos vendem os alimentos. Nesta situação, parece pertinente formular a seguinte questão: será que nós temos recursos não aproveitados que permitam a produção dos bens necessários para, pelo menos, melhorarmos o equilíbrio da nossa balança alimentar? Claro que temos: a terra está aí sem ser aproveitada, o sol brilha sem que dele tiremos o máximo partido, a água corre para o mar sem que a aproveitemos e, acima de tudo, os nossos recursos humanos não são utilizados.

O atual governo publicou o Despacho $n .^{\circ} 4680 / 2012$, de 3 de Abril, publicado no DR, no 67, $2 a$ Série, que refere "em conformidade com a estratégia «Europa 2020», garantir o desenvolvimento sustentável das zonas rurais. A proposta de regulamento do Parlamento Europeu e do Conselho relativo ao apoio ao desenvolvimento rural pelo Fundo Europeu 
Agrícola de Desenvolvimento Rural (FEADER) estabelece que o apoio ao desenvolvimento rural no período 2014-2020 se concentre em seis prioridades, de entre as quais ressaltam a de melhorar a competitividade de todos os tipos de agricultura e a viabilidade das explorações agrícolas, e a de promover a organização de cadeias alimentares, nomeadamente através da promoção em mercados locais e cadeias de abastecimento curtas."

No mesmo Despacho, lê-se que:

O Programa do XIX Governo Constitucional define como um dos objetivos estratégicos para a agricultura, o de «garantir a transparência nas relações produção-transformação-distribuição da cadeia alimentar, e promover a criação e dinamização de mercados de proximidade». Para que estes objetivos possam ser atingidos o Programa define medidas a implementar, nomeadamente a de «criar um estatuto jurídico flexível e um enquadramento fiscal e financeiro adequado, de forma a promover a melhoria da produtividade das explorações de menor dimensão», e a criação de mercados para a comercialização de produtos locais e de qualidade superior, em colaboração com o poder local. A iniciativa «Portugal sou eu», uma vez centrando-se na valorização da produção nacional, e em especial, neste contexto, a produção local, contribuirá para a prossecução dos objetivos definidos. Através da promoção de plataformas oferta-procura, pretende potenciar-se a comercialização e detecção de oportunidades de mercado, bem como tornar mais eficaz a articulação entre produtores e compradores.

Com este trabalho, pretende-se estudar o circuito de produção e comercialização de produtos com origem rural no concelho de Viseu, tendo para isso sido traçado um plano que se inicia com a identificação do problema, seguido da definição de objetivos e posterior análise do resultado de entrevistas a produtores locais e a consumidores citadinos, visando explorar o espaço existente para o desenvolvimento de negócios de proximidade.

Os produtos em causa neste trabalho, que são a inspiração para a criação de valor nesta cadeia tão fragilizada que é o meio rural, são os seguintes:

- Produtos hortícolas;

- Frutas;

- Ovos;

- Leite cru de vaca;

- Carnes de aves de capoeira;

- Carnes de lagomorfos;

- Carnes de animais de caça;

- Mel; 
- Compotas e outros produtos transformados de origem vegetal;

- Produtos à base de carne;

- Produtos à base de leite.

Questão de partida:

Dada a conjuntura socioeconómica atual poderá a produção e venda de produtos de produção rural de origem animal e vegetal, os seus circuitos de comercialização, e os circuitos de proximidade que se podem estabelecer entre a população rural e urbana no concelho de Viseu, contribuírem para criar valor económico e social?

Objetivo central do presente trabalho:

Estudar a forma de produção, distribuição e venda de produtos de produção rural, de origem animal e vegetal, os seus circuitos de comercialização, e os circuitos de proximidade que se podem estabelecer entre a população rural e urbana no concelho de Viseu.

Objetivos específicos:

Objetivo 1: Sensibilizar as famílias, para a possibilidade de verem incrementado o seu rendimento mensal com a venda de produtos hortícolas/produtos de origem animal de produção própria.

Objetivo 2: Avaliar a abertura e a disponibilidade por parte das famílias de agricultores, para a troca de produtos hortícolas/produtos de origem animal, por serviços que os seus clientes possam fornecer, nomeadamente horas de trabalho nas suas hortas/explorações agrícolas.

Objetivo 3: Avaliar o nível de recetividade dos clientes urbanos em possuírem para consumo produtos da horta, versus produtos de escala adquiríveis no comércio convencional.

Objetivo 4: Avaliar o nível de recetividade dos clientes urbanos em termos de troca de horas de trabalho por produtos hortícolas/produtos de origem animal.

\section{ELABORAÇÃO DE ENTREVISTAS, APRESENTAÇÃO E ANÁLISE DOS RESULTADOS}

$\mathrm{O}$ decorrer deste trabalho conduziu à necessidade de se obter informações com bastante especificidade, atendendo aos objetivos que foram traçados para o estudo. Como tal elegeu-se o método qualitativo de análise de dados. Com este método de pesquisa pretendeu-se garantir rigor na validade dos dados obtidos.

Definiu-se como método de recolha de informação, a entrevista individual a dois tipos distintos de população alvo. 
As entrevistas foram previamente elaboradas, com o intuito de obter respostas para os objetivos propostos neste trabalho. Definiu-se também que o teor das questões propostas aos entrevistados seria igual, para que os dados e a informação obtida fossem tratados de forma objetiva.

Em todas as entrevistas efetuadas foram omitidas as identidades dos intervenientes.

1. Elaboração e construção do inquérito e guião de entrevista

Foram construídas duas entrevistas distintas: uma destinada a clientes urbanos consumidores, e outra destinada a produtores rurais de produtos de origem vegetal e de origem animal.

As entrevistas foram todas presenciais, o que permitiu uma maior proximidade entre o entrevistado e o entrevistador.

\section{Caraterização da amostra e sua ligação aos objetivos definidos}

A amostra é constituída por 20 clientes urbanos e por 10 produtores rurais. O plano de amostragem foi elaborado de forma similar para os clientes urbanos e para os produtores rurais. Assim, foram definidos os seguintes critérios para serem aplicadas as entrevistas aos clientes urbanos (população alvo 1):

\section{População alvo 1:}

A população alvo possuía as características seguintes:

- Clientes que fazem normalmente as suas compras em superfícies comerciais;

- Habitantes de meios urbanos;

. Maiores de 18 anos,

. Residentes no concelho de Viseu.

Os critérios definidos para serem aplicados aos produtores de produtos de origem vegetal e origem animal (população alvo 2) foram os seguintes:

\section{População alvo 2:}

A população alvo possuías características seguintes:

- Produtores agrícolas que fazem comercialização de produtos de origem vegetal e animal;

. Habitantes de meios rurais;

- Maiores de 18 anos;

. Residentes no concelho de Viseu.

Para além destes critérios de base foi também considerada fundamental a realização de entrevistas a pessoas de grupos etários diversificados, com 
diferente estado civil e diversos estados de empregabilidade e dimensão familiar, permitindo assim a obtenção de uma amostra significativamente heterogénea.

Os resultados vão ser apresentados com base na recolha de todas as respostas que foram efetuadas aos clientes urbanos e aos produtores rurais.

Neste trabalho foi definido um objetivo geral e vários objetivos específicos. Com base neste pressuposto estratificaram-se as questões de acordo com os objetivos em questão, conforme está exposto nos quadros que se seguem.

\section{Quadro n. ${ }^{\circ}$ 1:}

Relação entre o objetivo específico $n .^{\circ} 1$ e as questões das entrevistas

\begin{tabular}{|c|c|}
\hline $\begin{array}{l}\text { OBJETIVO ESPECÍ́FICO } \\
\mathbf{1} \\
\text { Sensibilizar as famílias para } \\
\text { a possibilidade de verem } \\
\text { incrementado o seu rendimento } \\
\text { mensal com a venda de produtos } \\
\text { hortícolas/produtos de origem } \\
\text { animal de produção própria. }\end{array}$ & $\begin{array}{l}\text { Questão 6P: Exerce a agricultura a } \\
\text { tempo inteiro ou parcial? } \\
\text { Questão 7P: Qual a dimensão da sua } \\
\text { exploração agrícola? } \\
\text { Questão 8P: Tem na sua exploração } \\
\text { animais de interesse pecuário? Se sim, } \\
\text { quais? Vende alguns deles? } \\
\text { Questão 9P: Qual a área da sua } \\
\text { exploração destinada a produzir produtos } \\
\text { de origem vegetal e animal? } \\
\text { Questão 10P: A quem vende os seus } \\
\text { produtos? } \\
\text { Questão 11P: Qual o valor que obtém } \\
\text { por mês e, média com a venda deste tipo } \\
\text { de produtos? } \\
\text { Questão 12P: Qual a forma de os } \\
\text { fazer chegar aos seus clientes? }\end{array}$ \\
\hline
\end{tabular}




\section{Quadro n. ${ }^{\circ}$ 2:}

Relação entre o objetivo específico $n .^{\circ} 2$ e as questões das entrevistas OBJETIVO ESPECÍFICO 2

Avaliar a abertura e a disponibilidade por parte das famílias de agricultores, para a troca de produtos hortícolas/produtos de origem animal, por serviços que os seus clientes possam fornecer, nomeadamente horas de trabalho nas suas hortas/explorações agrícolas.

\section{Quadro n. ${ }^{\circ}$ 3:}

Relação entre o objetivo específico $n .^{\circ} 3$ e as questões das entrevistas

\begin{tabular}{|c|c|}
\hline 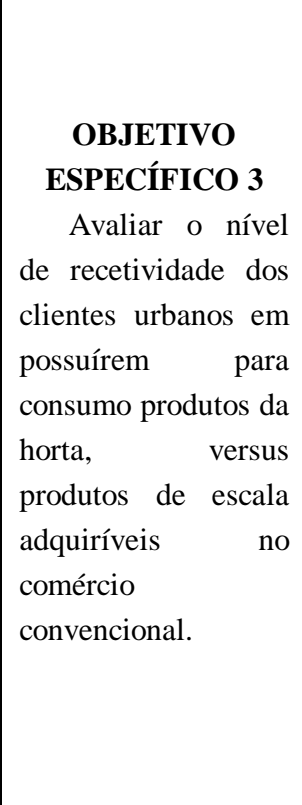 & $\begin{array}{l}\text { Questão 6C: Qual a regularidade das suas compras } \\
\text { de bens alimentares? } \\
\text { Questão 7C: Qual é o local onde mais } \\
\text { frequentemente efetua essas compras? } \\
\text { Questão 8C: Nas suas compras dá somente } \\
\text { preferência ao preço? Se não, quais são os outros fatores } \\
\text { que tem em consideração? } \\
\text { Questão 9C: Frequenta mercados semanais? Se sim, } \\
\text { quantas vezes por mês? } \\
\text { Questão 10C: Qual o gasto médio mensal do } \\
\text { agregado familiar em alimentação, expresso em } \\
\text { percentagem aproximada, relativamente ao rendimento } \\
\text { mensal do agregado familiar? } \\
\text { Questão 11C: Estaria disposto a comprar } \\
\text { diretamente ao produtor? Vê vantagens nessa forma de } \\
\text { comércio? } \\
\text { Questão 12C: Qual pensa ser a melhor forma dos } \\
\text { produtos de origem rural lhe chegarem a casa? }\end{array}$ \\
\hline
\end{tabular}




\section{Quadro n. ${ }^{\circ}$ 4:}

Relação entre o objetivo específico $n .^{\circ} 4$ e as questões das entrevistas

\begin{tabular}{|c|c|}
\hline $\begin{array}{c}\text { OBJETIVO ESPECÍFICO } \\
4\end{array}$ & $\begin{array}{l}\text { Questão 13C: Tem disponibilidade } \\
\text { para trocar horas do seu tempo a despender }\end{array}$ \\
\hline $\begin{array}{l}\quad \text { Avaliar o nível de } \\
\text { recetividade dos clientes urbanos } \\
\text { em termos de troca de horas de } \\
\text { trabalho por } \\
\text { hortícolas/produtos de } \\
\text { animal. }\end{array}$ & $\begin{array}{l}\text { em trabalho rural por produtos produzidos } \\
\text { em produtores rurais próximos? }\end{array}$ \\
\hline
\end{tabular}

\section{Caracterização dos clientes urbanos}

Dos 20 clientes urbanos entrevistados, as suas características são:

- 10 homens e 10 mulheres;

- Idades compreendidas entre os 28 e os 71 anos, com uma média de cerca de 44 anos;

- Média superior a 3 pessoas por habitação, o que ultrapassa a média de 2,7 membros por fogo encontrada no concelho de Viseu (quadro n. ${ }^{\circ} 8$ ). $\mathrm{Na}$ generalidade da amostra as famílias apresentam-se com mais de um elemento por fogo;

- Cerca de $70 \%$ dos inquiridos têm formação académica superior;

- Dos 20 elementos, 3 encontram-se desempregados, o que corresponde a $15 \%$ de desempregados, taxa de desemprego que, de acordo com quadro n..$^{\circ} 16$, se aproxima da taxa nacional do $2 .^{\circ}$ trimestre em Portugal.

\section{Caracterização dos produtores rurais}

Dos 10 produtores entrevistados, as suas características são:

- 5 homens e 5 mulheres;

- Idades compreendidas entre os 48 e os 75 anos, com uma média de cerca de 62 anos;

- Média superior a 2 pessoas por habitação. $\mathrm{Na}$ generalidade as famílias apresentam-se com mais de um elemento por fogo;

- Apenas um dos inquiridos tem formação académica superior.

\section{Apresentação de resultados}

Considerações relativas ao objetivo 1:

Quando se faz análise aos produtores e à forma como se dedicam à agricultura verifica-se que $90 \%$ dos inquiridos se dedicam a agricultura em tempo parcial, e apenas $10 \%$ se dedicam a tempo inteiro. 
O concelho de Viseu tem predomínio de explorações de pequena dimensão. Os inquiridos deste trabalho possuem áreas de exploração que vão desde os dois hectares até aos 300 metros quadrados, o que evidencia a existência de parcelas pequenas e de difícil rentabilização, sendo o espelho da realidade de minifúndio que caracteriza o concelho.

Verifica-se que a maioria dos produtores têm animais nas suas explorações, especialmente aves, e que em $70 \%$ dos casos vendem os ovos excedentários da sua produção. O problema que se coloca relativamente a estes produtores é que nenhum deles o faz de uma forma legal e correta, pois para isso deveriam estar inscritos na Direção Geral de Alimentação e Veterinária como produtores de ovos em pequena escala, de acordo com a Portaria 699/2008 de 29 de julho. No entanto, essa venda de ovos, por pequena que seja, origina sempre a entrada de algum dinheiro no agregado familiar.

Quando questionada a população de produtores acerca da dimensão da exploração que está destinada à produção de produtos hortícolas e animais, constata-se que nem todos dedicam a totalidade dos terrenos para essa atividade, o que diminui ainda mais a dimensão das explorações.

Constatou-se que o volume de vendas é muito reduzido, e que existem algumas particularidades que se elencam pela sua importância local:

- "Aqui há o hábito de entre vizinhos e amigos fazermos trocas do que produzimos.";

- "Vendo aos vizinhos e a quem passa aqui à porta.";

- "Vendo a clientes certos que também me levam umas verduras e uns ovos. São os mesmos de há muitos anos. Volta e meia aparecem uns novos trazidos pelos antigos,";

- "Vendo a uma amiga que tem banca na praça da cidade quando ela precisa e eu tenho.";

- "Vendo a duas senhoras amigas que vendem no mercado da cidade e que me compram quase tudo o que cultivamos.";

- "Vamos vendendo cada vez mais, estamos muito perto da cidade, e há alguma gente da aldeia a viver na cidade que nos vem comprar principalmente legumes e fruta."

Demonstrou-se a possibilidade real de aumento do rendimento das famílias rurais que produzem produtos de origem animal e vegetal: apesar dos valores se situarem entre os 50 e os 300 euros, estas quantias são significativas para famílias de baixos recursos, pois correspondem a um acréscimo efetivo dos seus rendimentos. 
Constata-se que estes agricultores não têm circuitos organizados de entrega dos produtos de que se possam socorrer, e que alguns deles não possuem sequer meios de transporte para fazer a distribuição. Os vizinhos, na generalidade, não são grandes clientes, pois pode inferir-se que vivendo em meio rural eles próprios também devem ter alguma produção própria.

Através destas respostas pode concluir-se que seria vantajoso para estes produtores estarem integrados num sistema de distribuição, o que lhes permitiria escoar mais eficazmente os seus produtos.

Considerações relativas ao objetivo 2:

A generalidade dos produtores reage favoravelmente ao desafio: apenas um dos inquiridos reage negativamente à presença de estranhos. $\mathrm{Na}$ generalidade, nove dos dez produtores acham esta troca benéfica, verificando-se até o relato de um produtor que conhece outra experiência e a explana da seguinte forma: "Conheço esse tipo de acordo, pois conheço em França explorações similares à minha que o praticam com resultados muito favoráveis, quer para quem produz quer para quem cede a sua força de trabalho em troca de produtos." Outro produtor tem receio de lidar com estranhos: "Gosto pouco de meter estranhos cá em casa, mas se fosse para trabalhar...".

Considerações relativas ao objetivo 3:

Da análise às respostas obtidas pode inferir-se que os clientes urbanos fazem compras com grande regularidade: num total de vinte indivíduos, quatro deles, ou seja $20 \%$, fazem compras em rotina diária. Os restantes $80 \%$, fazem compras todas as semanas, observando-se variações que vão desde uma vez por semana até às três vezes por semana. 100\% dos indivíduos acaba por fazer as suas compras nos supermercados e hipermercados. Apenas quatro dos entrevistados admitem recorrer pontualmente a outros pontos de venda, nomeadamente mercearias de bairro: "No hipermercado e na mercearia do bairro.", ou "Vou mais vezes à mercearia perto da minha casa,". O último entrevistado dá uma resposta mais interessante: "Abasteço-me preferencialmente em mercearias tradicionais, talhos, peixarias e em mercados municipais, e quando posso em mercados de venda direta de produtores. Mais raramente, quando tenho disponibilidade, faço compras na aldeia onde habita ainda a minha família, a agricultores locais, essencialmente de frutas e legumes. É tranquilizador sabermos o que estamos a comer, não acha?"

Um dos fatores determinantes para a escolha das grandes linhas de comércio é sem dúvida a acessibilidade a nível de horários, como refere 
este entrevistado: "Cada vez mais com maior frequência, infelizmente, utilizo os hipermercados e supermercados porque o tempo é escasso e estas superfícies estão abertas até mais tarde”. Ou ainda: “...com o nosso tempo reduzido é difícil ir a mercados locais.". Na realidade, os mercados locais têm um período de funcionamento muito restrito, o que lhes retira um fator de atratividade importante para os consumidores urbanos de hoje que privilegiam de sobremaneira o fator tempo.

Dos vinte inquiridos, catorze colocam o preço no topo das escolhas como se demonstra: "O preço é sempre preferencial."; "Sim, para mim o preço é determinante nas minhas escolhas.", ou ainda: "O preço, inegavelmente, é um fator que levo em consideração.".

No entanto, outros fatores são tidos em consideração pelos consumidores, que os consideram igualmente importantes: "O preço em primeiro lugar, a seguir a qualidade."; "Além do preço, dou também preferência à qualidade e á frescura."; "Relação qualidade preço. Promoções também são uma preferência", ou ainda "Para mim o preço é muito importante, mas a qualidade, a marca e a frescura também são fatores muito importantes que tenho em consideração."

Apenas um dos inquiridos faz alusão às marcas de confiança: "Dou preferência a marcas de confiança."

A cidade de Viseu tem um mercado semanal no centro da cidade, no qual os produtores rurais podem vender os seus produtos, preferencialmente no período da manhã, e habitualmente todos os dias com exceção do domingo.

Pela análise das respostas constata-se que são poucos os que visitam este mercado: apenas cinco dos vinte inquiridos referem aí adquirir produtos.

Várias são as justificações para a reduzida adesão da amostra a este tipo de local de compras:

- Falta de tempo: "Gostava mas não, porque não há tempo, os horários de trabalho são complicados, e os horários do hipermercado adequam-se melhor.";

- Falta de horários compatíveis: "Não por falta de disponibilidade de tempo e falta de oferta na nossa cidade em horários compatíveis.";

- Falta de oferta: "a oferta é pequena, aqui em Viseu só há a praça no centro da cidade e tem um horário que não me permite lá ir por causa do emprego."

No entanto, os inquiridos manifestam recetividade para mais deslocações a este tipo de locais, desde que os horários dos mesmos sejam 
alargados, tal como refere este entrevistado: "Não tenho muito tempo disponível e para além disso Viseu só tem um mercado rural no centro da cidade que funciona só de manhã e a essas horas estou a trabalhar."

$\mathrm{Da}$ análise das respostas pode-se constatar que com exceção de um entrevistado que não tem opinião formada, todos os outros entrevistados estão muito recetivos à compra direta ao produtor, sendo vários os fatores que concorrem para esse facto, nomeadamente:

- Preço e frescura, como se pode verificar neste depoimento: "Sim, em primeiro lugar o preço e a frescura", ou "era uma maneira de ter sempre produtos frescos da horta, o preço também poderia ser melhor em alguns produtos." Ou ainda: os produtos podem chegar mais frescos e são de melhor qualidade.";

- Justiça social: "sobretudo por uma questão de justiça social, pois o dinheiro deve ficar com quem produz e não com quem se limita a distribuir.";

- Desenvolvimento e dinamização da economia local, tal como se passa a transcrever: "Sim. Desenvolve a economia local", ou "as vantagens passam pela qualidade e preço dos produtos e pela possibilidade de dinamizar a produção agrícola local.”;

- Estimula a proximidade e confiança entre quem vende e quem compra, como se pode verificar neste depoimento: "Desenvolve... a proximidade entre quem compra e quem produz.", ou "uma questão cultural, e pela relação que se estabelece entre as pessoas." Ou ainda: "Para além disso para mim é importantíssimo saber, ter confiança no que estou a consumir. Repare, muitas das pessoas a quem compro conheço-as desde garoto. Inspiram-me confiança. Sei o que produzem e como produzem. E a outras conheço-as há anos e aprendi a confiar nelas. Não sou um fanático da agricultura biológica mas quanto menos químicos ingerirmos no que comemos tanto melhor.";

- A inexistência de intermediários, anulando assim a diluição de lucros, tal como refere um entrevistado: "Sim, vejo muitas vantagens, especialmente a possibilidade de não existirem intermediários.";

- O sabor dos produtos é diferente, e há quem valorize este fator, nomeadamente: "já faço isso quando compro na praça, os produtos são mais frescos e mais saborosos.";

- Sustentabilidade do meio rural como refere um dos entrevistados: "É importantíssimo, quanto a mim, apoiarmos o pequeno agricultor, a pequena produção, e dar-lhes condições de sobreviverem num mercado dominado pelos intermediários. Sem eles acaba-se a o mundo rural que eu e eles tanto prezamos." 
Preferencialmente, os clientes querem os produtos em casa. Transcrevese, para elucidar esta opinião, alguns dos seguintes depoimentos:

- "O ideal seria que eles viessem ter a casa.";

- "Haver um esquema de distribuição direta do produtor ao consumidor final, preferencialmente entrega ao domicilio, ou lojas de proximidade.";

- "Encomenda direta no produtor e ele trazer a casa no final do dia.";

- "O que gostaria mesmo é que os produtos me chegassem a casa.";

- "De preferência os produtos chegarem a casa por iniciativa do produtor.";

- Para mim a melhor forma seria me serem entregues em casa."

Por outro lado há clientes que referem também a possibilidade de comprarem em lojas de proximidade ou em mercearias.

O fator idade condiciona a saída de casa, e pode ser um fator interessante a explorar para a entrega direta ao domicilio, tal como refere um entrevistado: "Porque a idade já não ajuda muito, era bom que me levassem a casa a hortaliça."

Pelo exposto, também se pode inferir que o modelo de cliente urbano de hoje é alguém com pouco tempo e que tira vantagens dos produtos lhes chegarem à mão de uma forma facilitada.

Considerações relativas ao objetivo 4:

A maioria dos inquiridos estaria disposta a dedicar algum do seu tempo a ajudar os produtores rurais para em troca receberem produtos a custos reduzidos ou mesmo custo zero.

Do universo dos vinte entrevistados apenas quatro referem não ter interesse ou vontade de participar. Quanto aos restantes, apesar referirem que o tempo é escasso, é percetível uma vontade em participar. Este interesse em ser parte ativa expresso pelos consumidores urbanos é uma faceta a ter em consideração na perspetiva de, num futuro próximo, se explorarem soluções inovadoras que possam contribuir para viabilizar a agricultura rural.

\section{Outras considerações}

Quanto ao conhecimento por parte dos clientes urbanos do conceito de circuitos de proximidade em meio rural, verificou-se que dos vinte entrevistados, seis afirmaram perentoriamente o seu desconhecimento. Dois dos entrevistados acharam que tinham uma noção do que significava. Os restantes inquiridos afirmaram que "sabiam o que era", o que leva a 
concluir que apenas $60 \%$ dos inquiridos conhece o conceito de uma forma clara.

Todos os entrevistados reconhecem vantagens neste tipo de circuito de proximidade, mas também que a sensibilidade dos clientes urbanos é muito diversificada.

Para além da unanimidade no que respeita à qualidade e à frescura dos produtos nestes circuitos, elencam-se em seguida as expressões mais relevantes:

- "Pode aumentar o rendimento familiar de quem produz";

- "Um sistema mais justo para quem produz a uma melhor qualidade dos produtos";

- "Os produtos são apanhados numa fase de maturação ótima, o que permite uma qualidade excecional";

- "Permite que os pequenos produtores cresçam";

- "Troca de experiência e produtos, sinergias e inovação. Qualidade, frescura e economia de meios";

- "Dinamização da pequena produção, venda direta dos produtos ao consumidor sem intermediários, criação de postos de trabalho, contribuição da melhoria da qualidade de vida de quem produz, diversificação da atividade produtiva e acesso a produtos frescos de qualidade";

- "Escoar produtos em excesso";

- "A proximidade, confiança na produção e comercialização";

- "Relação que se estabelece, a confiança, sustentabilidade do meio rural";

- "Fomentar pequenos negócios, incrementar satisfação em produtores e consumidores";

- "Como se anulam os intermediários é possível o produtor ganhar mais um pouco, assim como quem está a comprar";

- "Encurta o tempo entre a produção e o consumo";

- "Deixa de haver intermediários no circuito";

- "Garantias de frescura e qualidade a quem consome, para além de terem uma vertente muito positiva na questão do custo dos produtos para o consumidor. Melhor e mais barato".

Constata-se assim que para além das características de qualidade, frescura e preço, obtidas através do encurtamento da cadeia de vendas, os clientes urbanos também estão sensíveis à justiça social por parte de quem produz. O crescimento da pequena produção e as suas vantagens, os aspetos de confiança e sustentabilidade do meio rural, e o fomento de pequenos negócios, são outros dos aspetos referidos pelos clientes. 
Verifica-se que a maioria dos produtores rurais, $70 \%$, desconhece que existe legislação específica na qual podem ser enquadrados, e desse modo poderem comercializar os seus produtos de uma forma legal e correta, sem terem qualquer receio de os exporem e comercializarem, já que daí não advirá qualquer tipo de penalização.

As sanções económicas por falta de licenciamento são um forte inibidor dos pequenos produtores que desconhecem as formas legais ao seu dispor para legalizarem as suas explorações. Esta inibição conduz a uma retração na produção e na comercialização dos produtos e, consequentemente, prejudicam o crescimento das zonas rurais.

Do mesmo modo os produtores rurais desconhecem que há legislação específica para o licenciamento das atividades de produção e venda de produtos de origem animal e vegetal. Pelas respostas apresentadas verificase que $70 \%$ dos inquiridos também desconhecem a quem se devem dirigir para a regularização da sua situação como micro produtores. Assim, esta informação deveria ser canalizada para as autoridades competentes nestas matérias, com o intuito de promover o esclarecimento dos produtores, criando a possibilidade de um maior número deles proceder ao licenciamento da sua atividade.

Os produtores do concelho de Viseu mostram-se principalmente preocupados com o escoamento dos produtos: "A maior dificuldade é sem dúvida escoar os produtos, fazer com que cheguem a outras pessoas." ou " É sempre escoar os produtos, aqui na aldeia vende-se pouco.”.

As dificuldades sentidas passam também pela criação de infraestruturas numa fase inicial, pelas dificuldades financeiras, e pela falta de pessoas que queiram trabalhar na agricultura.

Pela análise destes depoimentos verifica-se a existência de espaço para a criação de estruturas que estreitem estes circuitos de proximidade. As pessoas produzem e não têm a quem vender, mas percebem que se tivessem outro tipo de apoios teriam mais facilidade em escoar os seus produtos.

A implementação destes circuitos de proximidade poderia funcionar como um incentivo à produção.

\section{CONSIDERAÇÕES FINAIS}

Segundo Cristas (2013), “o Governo definiu como objetivo estratégico para a agricultura garantir a transparência nas relações produção transformação - distribuição da cadeia alimentar e promover a criação e 
dinamização de mercados de proximidade."

Neste âmbito, em 2012, o grupo de trabalho com vista à preparação de uma proposta de «Estratégia para a valorização da produção agrícola local» (GEVPAL) apresentou o seu relatório no final de dezembro. Nas suas conclusões, destaca a necessidade de se clarificar e adaptar as regras, nomeadamente as referentes às normas de comercialização, rotulagem, higiene dos géneros alimentícios de origem animal e licenciamento das unidades de transformação, à comercialização desses produtos em circuitos curtos."

Também Serra (2013) refere: "É importante que Portugal aposte na produção, divulgação e comercialização dos nossos produtos tradicionais, e deixe para trás políticas que considero ter sido uma perseguição imprópria à nossa cultura e ao nosso saber fazer. Há efeitos das opções passadas que não são já recuperáveis. Contudo é essencial resgatar o que ainda resta." Assim, considero essencial:

- Avaliar as derrogações possíveis na legislação para que seja permitido voltar o uso de materiais, utensílios e técnicas tradicionais para os nossos pequenos produtores.

- Divulgar, através de documentos objetivos, num português acessível, as normas mínimas, uniformes a todo o território nacional, para a legalização e certificação dos pequenos negócios de produtos tradicionais. Para tal, urge que sejam fomentadas ações de divulgação e esclarecimento, junto dos agentes económicos potencialmente abrangidos a nível setorial, quanto às exigências normativas, tendo em conta os documentos de orientação divulgados pela Comissão Europeia.

- Possibilitar a venda direta dos nossos produtos tradicionais nos quase extintos mercados de proximidade, onde todos os pequenos produtores tenham acesso e possam vender aquilo que colheram da sua terra, o que produziram na sua pequena queijaria ou mesmo a doçaria que fizeram na sua cozinha, sem que sejam perseguidos por uma qualquer entidade cinzenta, que aplica regras difusas.

A atividade agrícola continua a ser uma importante fonte de alimentos e de rendimento para a maior parte das famílias rurais, possibilitando simultaneamente a criação de postos de trabalho, o aumento dos rendimentos, bem como a ampliação e a melhoria da oferta de produtos alimentares quer a nível regional como a nível nacional.

Hoje, é também uma realidade a criação de valor por parte dos produtos originários de pequenas produções, realizadas em pequenas empresas familiares, através de incorporação de tecnologia e de serviços, que possibilitam o estímulo e a implementação do conceito de 
empreendedorismo, e a criação de marcas com base no conceito de produto local.

É de todo o interesse para o país que, a nível político, seja dada maior importância à aquisição de alimentos produzidos localmente, especialmente no que concerne ao fornecimento de organismos públicos (hospitais, cantinas escolares, instituições de apoio à terceira idade). As cantinas escolares podem ter um papel decisivo no futuro da sustentabilidade da pequena produção rural, pois para além de serem um cliente assíduo, podem exercer um papel didático mostrando aos seus alunos de onde provêm os alimentos que consomem.

É fundamental adequar o quadro legislativo para as microproduções, o que só será possível quando a classe política e o legislador fizerem o exercício inverso: colocarem-se na pele dos produtores e aquilatarem a dimensão dos estrangulamentos que são colocados a quem pretende ter em meio rural o seu próprio negócio de pequena escala.

É essencial valorizar os produtos agroalimentares locais. Os produtos da nossa terra fazem parte da nossa dieta, da nossa identidade e da nossa cultura.

A relação direta que se pode estabelecer entre o produtor local e o consumidor final, o consumidor urbano, traz para ambos várias vantagens:

- Pagamento imediato;

- Aumento da autoestima dos produtores, pois o que produzem é vendido e consumido, acrescentando valor ao seu orçamento mensal;

- Reconhecimento dos produtores;

- Estímulo do empreendedorismo;

- Regulação das relações de equilíbrio entre a produção e o consumo;

- Promoção de mais-valias na cadeia de valor;

- Estímulo ao consumo dos produtos da época;

- Promoção de melhor qualidade;

- Manutenção de terrenos ocupados;

- Valorização das espécies nacionais e regionais;

- Promoção da sustentabilidade.

As principais dificuldades que se deparam são:

- Quadro legislativo desadequado;

- Falta de estratégia governamental para esta área, sendo necessária a implementação de uma política de integração local;

- O poder negocial e aquisitivo das centrais de compras que lhes permite obter preços de aquisição concorrenciais, desequilibrando a seu favor a competição com as pequenas produções; 
- Impossibilidade ou falta de dimensão no acesso a concursos públicos.

\section{REFERÊNCIAS}

Cristas, A. (2013). Importância dos produtos locais na dinamização económica e social dos territórios. Em Rede, Revista da Rede Rural Nacional, $\quad 3, \quad 2-3 . \quad$ Retirado de http://www.rederural.pt/images/stories/Revistas_emRede/emRede3.p df

Pinheiro, António C. e Coelho, José C. (2011). "Uso Produtivo da terra" Cadernos de Economia n. 97 , Ano XIV, Out/Dez., (pp.47-50). Retirado de: http://dspace.uevora.pt/rdpc/handle/10174/3524

Serra, N. (2013). Valorizar a tradição e os produtos locais: o que é nosso é bom. EM REDE, Revista da Rede Rural Nacional, 3, 4. Retirado de http://www.rederural.pt/images/stories/Revistas_emRede/emRede3.p df

Tibério, L. M., \& Cristóvão, A. (2005). Microproduções e desenvolvimento local. In L. M. Tibério, A. Cristóvão \& V. C. Diéguez (Eds.), Microproduções Agrícolas e Desenvolvimento Local no Douro - Duero (1 ed., pp. 15-28). Vila Real - Portugal: GRECA artes gráficas.

\section{BIBLIOGRAFIA CONSULTADA}

Barros, G., (2006). Agricultura familiar. CEPEA. Retirado de: http://www.cepea.esalq.usp.br/especialagro/EspecialAgroCepea_9.do c.

Cardoso, A., \& Silva, M. (2010). Juntas de freguesias, colectividades e câmara municipal: poderes, conflitos e mediações. In Figueiredo, E.; Kastenholz, E.; Eusébio, M.C.; Gomes, M.C.; Carneiro, M.J.; Batista, P.; Valente, S. (Eds.), IV CONGRESSO DE ESTUDOS RURAIS Mundos Rurais em Portugal - Múltiplos Olhares, Múltiplos Futuros (p. 1169 - 1186). Retirado de http://www.academia.edu/322777/_Caminhos_Possiveis_do_Rural_e m_Portugal_As_prioridades_do_novo_programa_de_desenvolviment o_rural_

CEPAL, (2013, setembro). Agricultura familiar e circuitos curtos. Retirado de http://paa-africa.org/pt/2013/09/03/cepal-organizaseminario-sobre-agricultura-familiar-e-circuitos-curtos/ 
Cristóvão, A., Tibério, M., Teixeira, M. (2003), Propostas de Estratégias de Valorização. "Terras de Bouro: Estudo e Caracterização de produtos Locais". Câmara Municipal de Terras de Bouro (Ed.)

Cruz, F. T. D. \& Schneider, S. (2010). Qualidade dos alimentos, escalas de produção e valorização de produtos tradicionais. Revista Brasileira de Agroecologia, 5(2), 22-38. Retirado de http://www.ufrgs.br/pgdr/arquivos/778.pdf

Favareto, A. (2011, junho). Economia verde e um novo ciclo de desenvolvimento rural. Economia Verde - Desafios e oportunidades, 8, 131-142. Retirado de http://www.conservation.org.br/publicacoes/files/Paginas de PoliticaAmbiental08favareto.pdf

Fernandes, A. (2011). Do discurso ao projecto urbano de reinvenção da ruralidade. (Tese de Doutoramento) Retirado de http://hdl.handle.net/2445/42008

GEVPAL. (2012). Ministério da Agricultura, do Mar, do Ambiente e do Ordenamento do Teritório, Direção-Geral de Agricultura e Desenvolvimento Rural. Relatório do grupo de trabalho «estratégia para a valorização da produção agrícola local - GEVPAL». Retirado de: http://www.rederural.pt/images/stories/Zira_2/relatorio gevpal_sefdr final.pdf

Ikerd, J. (2009, January 21-24). Why sustainable family farms are critical to the future of the world. 18th annual practical tools and solutions for sustainable family farms conference,, Southern SAWG, Chattanooga, TN.

Em http://web.missouri.edu/ikerdj/papers/Chattanooga $\quad--\quad$ SSWAG Family Farms.htm

Mior, L. C. (2007). Agricultura familiar, agroindústria e desenvolvimento territorial. Colóquio Internacional de Desenvolvimento Rural Sustentável. Florianópolis, 22.

Muller, Ana Luiza; Kunrath Silva, Marcelo; Schneider, Sergio (2012). A construção de Políticas Públicas para Agricultura Familiar - o caso do Programa de Aquisição de Alimentos. Estudos, Sociedade e Agricultura, vol. 20 n.1. Rio de Janeiro, 2012.

Oliveira Roca, M. N., \& Marquinho, R. (2010). Sustentabilidade demográfica da agricultura no centro-sul português em risco de desertificação. In M. N. Oliveira Roca (Ed.), Desertificação, Desenvolvimento Sustentável e Agricultura Familiar, Recortes no 
Brasil, em Portugal e na África (1 ed.). PB, Brasil: Editora Universitária UFPB.

Pais, C., \& Gomes, B. (2008). O Espaço Rural no âmbito das Políticas de Desenvolvimento - O Caso do Pinhal Interior.

Ramos Caetano, M. (2010). Novos caminhos para a agricultura familiar na era da sustentabilidade. Sociedade e Desenvolvimento Rural on line, 4(1), 38-56. Retirado de http://www.inagrodf.com.br/revista

Ribeiro Lima, S. R. (2007). Ruralidade: O debate sobre o velho e o novo no meio rural. XIII Congresso Brasileiro de Sociologia, Agricultura familiar, Desenvolvimento Rural e Segurança Alimentar, 29 de maio a 1 de Junho, UFPE, Recife (PE).

Roxo, M. J., \& Almeida Neves, B. M. (2000). A percepção do fenómeno da desertificação em Portugal e no Brasil: a importância de informar a sociedade. In M. J. Editora universitária (Ed.), Desertificação, Desenvolvimento sustentável e agricultura familiar recortes no Brasil, em Portugal e em África (pp. 9-27). João Pessoa - PB: Ministério do Ambiente.

Ruivo, P. (2006). Marketing e territórios rurais procura e oferta de amenidades, Dissertação de Doutoramento em Engenharia Agronómica. Lisboa).

Schneider, S. (2009). Território, ruralidade e desenvolvimento. In F. Velásquez Lozano \& J. Medina (Eds.), Las Configuraciones de los Territorios Rurales en el Siglo XXI (1 ed., Vol. 1, pp. 67-108). Retrieved from http://www.ufrgs.br/pgdr/arquivos/726.pdf

Tibério, L. M., Cristóvão, A., \& Abreu, S. (2005). Propostas para a valorização das microproduções. In A. Cristovão, L. M. Tibério \& V. C. Diéguez (Eds.), Microproduções Agrícolas e Desenvolvimento Local no DOURO DUERO (1 ed., pp. 179-188). Vila Real Portugal: Greca artes gráficas.

Traldi, D. R. C., \& Almeida, L. M. D. M. C. (2012). Políticas públicas de transferência de renda e a questão da segurança alimentar dos beneficiários: efetividades e entraves do Programa Bolsa Família. Política \& Sociedade, 11 (21), 137-171.

Velásquez Lozano, F., \& Medina , J. G. F. (2009). Las configuraciones de los territorios rurales en el siglo XXI. (1 ed., Vol. 1, pp. 67-108). Bogotá/Colômbia: Editorial Pontifícia Universidad Javeriana.

Wolfenson, K. D. M. (2013). Preparations and outcomes of the 2012 united nations conference on sustainable development (rio 20). In Coping with the food and agriculture challenge: smallholders' agenda. ROME, Italy: Natural Resources Management and 
Environment Department, Food and Agriculture Organization of the United Nations. Em

http://www.fao.org/fileadmin/templates/nr/sustainability_pathways/do cs/Coping_with_food_and_agriculture_challenge_Smallholder_s_ag enda_Final.pdf

\section{Legislação}

Decreto-Lei n. ${ }^{\circ}$ 169/2012, de 1 de Agosto, Diário da República, $n .^{o}$ 148/12, I série - 1 de agosto de 2012. Ministério da Economia e do Emprego. Lisboa.

Despacho n. ${ }^{\circ}$ 4680/2012, de 3 de Abril, Diário da República, $n^{\circ}$ 67/12, II Série, de 3 de abril de 2012. Presidência do Conselho de Ministros e Ministérios da Economia e do Emprego e da Agricultura, do Mar, do Ambiente e do Ordenamento do Território. Lisboa.

Portaria n. ${ }^{\circ}$ 699/2008 de 29 de Julho, Diário da República, n. 145/08, I série, de 29 de Julho de 2008. Ministérios da Economia e da Inovação e da Agricultura, do Desenvolvimento Rural e das Pescas. Lisboa.

Regulamento (CE) N. ${ }^{\circ}$ 178/2002 do Parlamento Europeu e do Conselho de 28 de janeiro de 2002, Jornal Oficial da União Europeia. L 31 de 1.2.2002, PT.

Regulamento (CE) N. ${ }^{\circ}$ 2073/2005 da Comissão de 15 de novembro de 2005, Jornal Oficial da União Europeia. L 338 de 22.12.2005. PT.

Regulamento (CE) N. ${ }^{\circ} 852 / 2004$ do Parlamento Europeu e do Conselho de 29 de abril de 2004, Jornal Oficial da União Europeia. L 139 de 30.4.2004. PT.

Regulamento (CE) N. ${ }^{\circ}$ 853/2004 do Parlamento Europeu e do Conselho de 29 de abril de 2004, Jornal Oficial da União Europeia. L 226 de 25.6.2004. PT. 